\title{
Research Paper: Psychometric Properties of the Committed Action Questionnaire, the Persian Version
}

\author{
Maryam Mazloom $^{1 *}$ (D), Shahram Mohammadkhani' ${ }^{\text {(D), Mehdi Akbari }}{ }^{1}$ (D), Jafar Hasani1 ${ }^{1}$ (D)
}

1. Department of Clinical Psychology, Faculty of psychology and Education, Kharazmi University, Tehran, Iran.

\begin{tabular}{|c|c|}
\hline $\begin{array}{l}\text { Use your device to scan } \\
\text { and read the article online }\end{array}$ & Crtation: Mazloom, M., Mohammadkhani, S., Akbari, M., \& Hasani, J. (2020). Psychometric Properties of the Committed \\
\hline 口ita & $\begin{array}{l}\text { Action Questionnaire, the Persian Version. Journal of Practice in Clinical Psychology, 8(2), 153-162. https://doi.org/10.32598/ } \\
\text { jpcp.8.2.680.1 }\end{array}$ \\
\hline 口달. & dolisttps://doi.org/10.32598/jpcp.8.2.680.1 \\
\hline
\end{tabular}

\section{(c) (1) (8)}

Article info:

Received: 20 Oct 2019

Accepted: 14 Feb 2020

Available Online: 01 Apr 2020

Keywords:

Committed action, Validity, Reliability, Psychometrics, Confirmatory factor analyses

\section{ABSTRACT}

Objective: This study aimed to evaluate the psychometric properties of the Persian version of the Committed Action Questionnaire (CAQ-8) in a non-clinical sample. The study evaluated the factor analyses, reliability, and validity of the CAQ-8 in an Iranian sample.

Methods: The psychometric properties of the CAQ-8 were investigated in a Persian student $(\mathrm{n}=180)$, through convenient sampling for data gathering. Participants filled out a battery of questionnaires, including CAQ-8, medical outcomes study questionnaire 36-item Short-Form Health Survey (SF-36), Acceptance and Action Questionnaire (AAQ-II), and Depression, Anxiety, And Stress Scale (DASS-21). Confirmatory factor analyses and goodness of fit indexes were used to examine the reliability and validity of the Persian version of the CAQ-8.

Results: The Persian version of the CAQ- 8 revealed satisfactory levels of internal consistency $(\alpha=0.77)$, and significant association with various indexes of theoretically-related instruments such as DASS-21, SF-36, and AAQ-II. Confirmatory factor analyses demonstrated that the Persian version of the CAQ-8 yielded a 7-item questionnaire by the two-factor model.

Conclusion: The Persian version of CAQ appears to be a valid, reliable, and adequate measure for the assessment of the concept of committed action in the Iranian sample.

\section{* Corresponding Author:}

Maryam Mazloom, PhD. Candidate

Address: Department of Clinical Psychology, Faculty of psychology and Education, Kharazmi University, Tehran, Iran

Tel: \pm 98 (911) 2349943

E-mail:mazloom.maryam@yahoo.com 


\section{Highlights}

- Persian version of the CAQ has good internal consistency.

- Persian version of the CAQ indicated the convergent validity.

- Confirmatory Factor Analysis yielded to the two-factor model.

- Persian version of the CAQ revealed a good fit to the empirical data.

\section{Plain Language Summary}

We aimed to do a psychometric evaluation of the Persian version of the Committed Action Questionnaire (CAQ) in a nonclinical sample. According to the Confirmatory factor analyses and goodness of fit indexes, the Persian versions of the CAQ demonstrated high levels of internal consistency and satisfactory relationships with various indexes of theoretically related concepts. The Persian version of CAQ appears valid, reliable, and adequate as a measure for the specific assessment of the concept of committed action in the Iranian sample.

\section{Introduction}

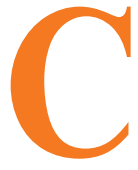

ommitted action is an important process in the psychological flexibility model. It is conceptualized as the practice of behaviors consistent with a meaningful life that includes living by personal values, carrying out personal goals, despite experiencing unpleasant events, thoughts, emotions, and obstacles everyone will encounter (Forman, Herbert, Moitra, Yeomans, \& Geller, 2007; McCracken, 2013). Committed action facilitates a moment-by-moment ability to discriminate between responses that are intended to avoid pain and to pursue what is valued. Furthermore, committed action requires a balance between persistence and flexibility, where goals underlying meaningful values are pursued despite discomfort or failure, but can be abandoned if they are repeatedly unmet (Bailey, Vowles, Witkiewitz, Sowden, \& Ashworth, 2016; McCracken, 2013).

Until the past decade, no specific measure was available for the assessment of the committed action concept. For the first time, McCracken (2013) developed a self-report measure (committed action questionnaire [CAQ-24]) to assess the committed action in individuals with chronic pain. The preliminary results supported the internal consistency of the CAQ and its correlation with another component of the psychological flexibility model. Similarly, CAQ could explain the significant variance in various psychopathologic conditions, such as mental, and social functioning, and general health, (McCracken, 2013).
Initially, CAQ was developed as a 24-item questionnaire for the assessment of the committed action. Then, this measure reduced to an 18-item questionnaire, entailing flexible persistence in goal-directed behavior in the framework of the psychological flexibility model (McCracken, Chilcot, \& Norton, 2015).

Initially, the committed action questionnaire (McCracken, 2013) was developed in a chronic pain context and was proved to be a valid and reliable instrument. It was correlated with several concepts namely acceptance, depression, and general health (McCracken, 2013). Recently, this questionnaire was utilized in various populations such as those with fibromyalgia (Galan et al., 2019) and burn injury (Shepherd et al., 2019).

As noted in the previous studies, the short version of the CAQ can be a helpful instrument for data gathering; therefore, CAQ-18 was reduced to an 8-item measure (McCracken, Chilcot, \& Norton, 2015). Currently, the process of committed action can be measured by the short form of CAQ (Trindade, Marta-Simões, Ferreira, \& Pinto-Gouveia, 2018; McCracken, 2013).

Recently we are observing the increasing interest in the utilization of CAQ in different languages, for example, psychometric evaluation of the Dutch version of CAQ-8 in a nonclinical sample (kraiss, 2014), validation of the Committed Action Questionnaire (CAQ-8 and CAQ-18) in a Swedish sample with chronic pain (Akerblom, Perrin, Fischer, \& McCracken, 2016), preliminary analysis of Chinese version of QAC (Wong, McCracken, Wong, Chen, Chow, \& Fielding, 2016) and also analyzing the 
psychometric properties of the CAQ-8 in both healthy Portuguese individuals and women with cancer (Trindade et al., 2018).

Nonetheless, Trindade et al. (2018) suggest that CAQ-8 is an adequate measure for the assessment of the committed action concept in individuals with cancer and healthy people both. The development of CAQ-18 and CAQ-8 was based on populations with chronic pain; therefore, the generalizing of psychometric findings to other samples require more investigation in various cultures and populations (McCracken, Chilcot, \& Norton, 2015). Hence, this study aimed to analyses the psychometric properties of the CAQ8 in Iranian healthy individuals.

We sought to validate the Persian version of the CAQ-8 and to investigate the generalization of the previous studies (Akerblom et al., 2016; Bailey et al., 2016; McCracken, 2013; McCracken, Chilcot, \& Norton, 2015; Trindade et al., 2018). To explore the psychometric properties of the Persian version of the CAQ- 8 , exploratory and confirmatory factor analysis were conducted to clarify the factor structure of CAQ-8 in the Persian population.

\section{Methods}

\section{Study design}

The present study is a correlational cross-sectional study.

\section{Study participants}

The study participants were recruited from University students. We calculate the sample size according to 15 cases per each indicator (Stevens, 2012). Given the probability of attrition and missing data, we considered 180 cases for this study. The inclusion criteria were students 18 years or older and able to understand and read the Persian language. The exclusion criteria were missing information, disinterest for participation in the study, and non-Iranian students. All participants gave their informed consent before participation, and ethical approval for this research was granted by the Kharazmi University Ethics Committee. Notably, this study was conducted in the general population, and SF-36 was utilized as an instrument for clinical screening. The convenience sampling method was utilized for data gathering, and the students in Kharazmi University Campus, dormitory, and classroom filled out a battery of questionnaires. Finally, the study included 180 university students (136 women [75.55\%], 44 men [24.44\%]) aged between 18 and 48 years $(\mathrm{M}=26.49, \mathrm{SD}=5.99$ years $)$. Participants were mostly single (72.8\%), and their education levels were BS. (44.4\%), MS. (19.4\%), and PhD. (33.9\%).

\section{Translation of the CAQ-8}

The translation of the CAQ-8 from the original English version to the Persian language was performed in several steps. First, CAQ-8 was translated from English to Persian by a Persian clinical health psychologist fluent in English and with adequate information about the committed action construct. Then the questionnaire was back-translated. The translated questionnaire was changed according to the recommendation of the expert group (three associate professors in clinical psychology, a $\mathrm{PhD}$. candidate in health psychology, and an expert in English). Finally, the Persian version of the CAQ-8 was administered to 180 university students.

\section{Study measures}

All participants completed a battery of questionnaires, including demographic questions and the following instruments. Committed action questionnaire (shortened version) (McCracken, Chilcot, \& Norton, 2015)

Committed Action Questionnaire (CAQ-8) consists of two components, which includes eight items. Both components (positively phrased and negatively phrased) were taken from the original full-length CAQ. Like the original one, the short version has strong psychometric properties (McCracken, Chilcot, \& Norton, 2015). Reliability, validity, and factor analysis of CAQ-8 in other languages such as Swedish (Akerblom et al., 2016), Chinese (Wong et al., 2016), and Portuguese version (Trindade et al., 2018) indicated sufficient similar results. Medical outcomes study questionnaire short form 36 items health survey (Ware, \& Gandek, 1998).

The short form 36 items health survey (SF-36) is a widely used measure of health and functioning in health research (Ware \& Gandek, 1998). The SF-36 involves eight subscales and covers several aspects of functioning and health, such as physical, emotional, and social functioning and performance. Higher scores indicate a better health state. The scoring for any subscale is different (for example: ranging from 1 to 3 for physical functioning subscale, and from 1 to 6 for vitality subscale) ( Ware, 1993; McHorney, Ware, \& Raczek, 1993; Ware, John, \& Sherbourne, 1992). The psychometric evaluation of the SF36 demonstrated strong reliability $(\alpha=0.8)$ (McHorney, Ware, Lu, \& Sherbourne, 1994; Ware, \& Sherbourne, 1992). The psychometric properties of the Persian version of SF-36 used in this study have been confirmed by Montazeri, Goshtasebi, Vahdaninia, and Gandek (2005). The internal consistency indicated the reliability standards for all SF-36 subscales (Cronbach $\alpha=0.65$ to 0.90) (Montaz- 
eri et al., 2005). The SF-36 is a wildly used self-report instrument for measuring general health. Acceptance and action questionnaire (Bond et al., 2011).

The Acceptance and Action Questionnaire (AAQ) was developed to assess the psychological processes and psychological flexibility (Hayes et al., 2004) and considered as a measure of two constructs (acceptance and experiential avoidance). AAQ-II includes two subscales (avoidance, and control). The original AAQ (include 22 items) was revised and reduced to 10 items (Bond et al., 2011). Each item is rated from 1 (never true) to 7 (always true). A psychometric assessment of the AAQ-II revealed high internal consistency and validity. Its alpha coefficient ranged from 0.78 to 0.88 , and the test-retest reliability values were 0.81 ( 3 months) and 0.79 (12 months). The AAQ-II with better psychometric consistency, rather than AAQ-I ( $\mathrm{r}=0.97)$ (Bond et al., 2011). The psychometric properties of the AAQ-II (Persian version) indicated the good reliability indexes (Cronbach $\alpha=0.89$ and test-retest reliability $=0.71$ ) (Abbasi, Fata, Mouludi, \& Zarrabi, 2013).

Depression, Anxiety And Stress Scale (DASS-21) (Lovibond \& Lovibond, 1995):

The depression, Anxiety, and Stress Scale (DASS-21) is a 21-item self-report scale with three subscales: depression, anxiety, and stress. The respondents utilized a 4-point scale to represent the severity of distress in the recent week (Lovibond \& Lovibond, 1995). The previous studies indicated that the DASS-21 has good psychometric properties. The DASS-21 subscales can measure distress symptoms (Henry \& Crawford, 2005). The Cronbach alpha coefficients for DASS-21 subscales, were 0.94 (for depression subscale), 0.87 (for anxiety subscale), and 0.91 (for stress subscale) (Antony et al., 1998). Similarly, in the Persian version of DASS-21, a 3-factor structure, reliability, and validity of the DASS-21 were supported by the data, which suggests the DASS-21-Persian version has satisfactory psychometric properties in a nonclinical population (Asghari, Saed, \& Dibajnia, 2008).

\section{Statistical analysis}

To test the reliability, corrected item-total correlations and Cronbach $\alpha$ were used to examine the internal consistency of the Persian version of CAQ-8. According to Kline (2013), the Cronbach alpha values more than 0.60 and 0.70 indicate an acceptable and good internal consistency, respectively.
To test the validity, the convergent and divergent validities were examined through the correlation test between the Persian version of the CAQ-8 and other measures of SF-36, AAQ-II, and DASS-21. The Pearson correlation coefficients were considered as strong $(\mathrm{r}=0.5$ to $\mathrm{r}=1.0)$, moderate $(r=0.3$ to $r=0.5)$ or weak $(r=0.1$ to $r=0.3)(\mathrm{Co}$ hen, Swerdlik, \& Phillips, 1996).

The factor (dimensional) structure of CAQ-8 was assessed using both explanatory and confirmatory factor analysis. Confirmatory Factor Analysis (CFA) was utilized to investigate whether the factor structures in the Persian population matched the original two-factor models. CFA examines the matching between the present hypothesized factor structure and the covariance among the original scale's items (Van Prooijen \& Van Der Kloot, 2001; Watkins, 1989). Based on the theoretical foundation of CAQ, we utilize the oblimin rotation. The maximum likelihood estimation was utilized for analyses. Item loadings were considered satisfactory if they were 0.32 or above (Tabachnick \& Fidell, 2013).

For analyzing the results from the CFA, the following goodness of fit indices were selected: the relative/ normed Chi-Square statistic $\left(\mathrm{x}^{2} / \mathrm{df}\right)$ (acceptable fit $<5$ ), independence AIC (Akaike information criterion), the Comparative Fit Index (CFI) (good fit >0.90) (Knight, Virdin, Ocampo, \& Roosa, 1994), the Root Mean Square Error Of Approximation (RMSEA), as a well-established fit statistic which can be considered one of the most informative, and also the Standardized Root Mean Square Residual (SRMS). The smaller values of RMSEA and SRMS indicate the better fit of the model (e.g. $<0.05$ ). Other fit indexes are the Goodness of Fit Index (GFI), Relative Fit Index (RFI), and Normed Fit Index (NFI) that ideally the values greater than 0.90 indicate an acceptable fit (Meyers, Gamst, \& Guarino, 2016). IBM SPSS V. 24 (Spss, 2016), and LISREL 8.54 were utilized for psychometric analyses.

\section{Results}

Regarding reliability, the scores of the 8-item version of the CAQ showed good internal consistency based on the Cronbach $\alpha$ value, which was 0.77 for the Persian version of the CAQ-8 total scores. These values for positively phrased and negatively phrased subscales were 0.90 and 0.61 , respectively. If item 5 is deleted, the Cronbach $\alpha$ exceeds 0.85 for total scores and 0.73 for negatively phrased subscale.

For investigating the construct validity, the correlations between the CAQ-8 and the other relevant instruments 
namely AAQ-II, DASS-21, SF-36, and their subscales were examined. There is a negative correlation between CAQ-8 total score and also all subscales of DASS-21. The relationships between CAQ-8 and two other instruments (AAQ-II and SF-36) were significantly positive (Table 1).

Regarding the item analysis, the item-test correlations were well over 0.50 , except for item 5 . It suggests that by removal of this item, the scale would be homogeneous. The observed mean for the total score of CAQ-8 was 31.08 ( $\mathrm{SD}=8.46)$. The majority of items were positively correlated with each other, except for item 5 that had a negative correlation with other items (Table 2). Similarly, this item has a minimum of commonalities (Extraction solution $=0.37$ ) in factor loading.

Kaiser-Meyer-Olkin, a measure of sampling adequacy (0.80), demonstrated the acceptable inter-item correlations to conduct confirmatory factor analysis. As a general heuristic (Kaiser, 1970, 1974), a value of 0.70 or above is considered adequate. According to Bartlett's test of sphericity (Approx. Chi-square $=740.947 ; \mathrm{df}=28$; Sig. $=0.000$ ), the null hypothesis of a lack of sufficient correlation between variables was rejected. In other words, KMO and Bartlett's values showed an adequate sample size for conducting confirmatory factor analysis (Meyers, Gamst, \& Guarino, 2016).

In the principal component solution, initial communality values in all items were equal to 1 , and extraction (final) values indicate that all variables were participating or contributing to the component solution. Minimum and maximum extraction belonged to item $5(0.37)$, and item $2(0.83)$.

As mentioned by Tabachnick and Fidell (2013), a robust solution should account for at least $50 \%$ of the variance. Confirmatory factor analysis revealed the 2 components with eigenvalues of 1 or above, which accounted for $66.48 \%$ of the variance. Oblimin rotation revealed a two-factor pattern. The first factor (four positively phrased items) explained $46.15 \%$ of the common item variance, and the second factor (negatively phrased items) explained $20.33 \%$ of the total variance. The correlation coefficient between these two factors was 0.38 .

Four items (CAQ1, CAQ2, CAQ3, and CAQ4) had the highest factor loadings on factor 1 , and three items (CAQ6, CAQ7, and CAQ8) had factor loadings on factor 2. One item (CAQ5) has a common factor loading on both factors. Table 3 shows descriptive information and item loadings from the confirmatory factor analysis. Item loadings for the Persian version of CAQ-8 were satisfactory (for factor 1 ranged from 0.89 to 0.75 , and for factor 2 ranged from 0.46 to 0.72 ). The loading for item 5 (I find it difficult to carry on with an activity unless I experience that it is successful) was common on both factors 1 and 2 . Thus, this item was deleted and excluded from the questionnaire.

Regarding the goodness of fit indexes, the results revealed the two-factor structure of CAQ (by deletion of item 5). This model represented a good fit for the empirical data in a non-clinical sample. Except for item 5 (standardized coefficient $=0.18$ ), all coefficients were significant. The goodness of fit indexes are presented in Table 4. For the two-factor model, all fit indexes indicated satisfactory results.

Finally, the local adjustment of the model was acceptable, with SRWs between 0.86 (item 8) and 1.71 (item 1 and 2) and SMCs between 0.34 (item 2) and 1.62 (item 4). Beta coefficients of structural equation modeling of CAQ are demonstrated in Figure 1.

Table 1. The correlations between the Committed Action Questionnaire (CAQ-8) and criteria variables

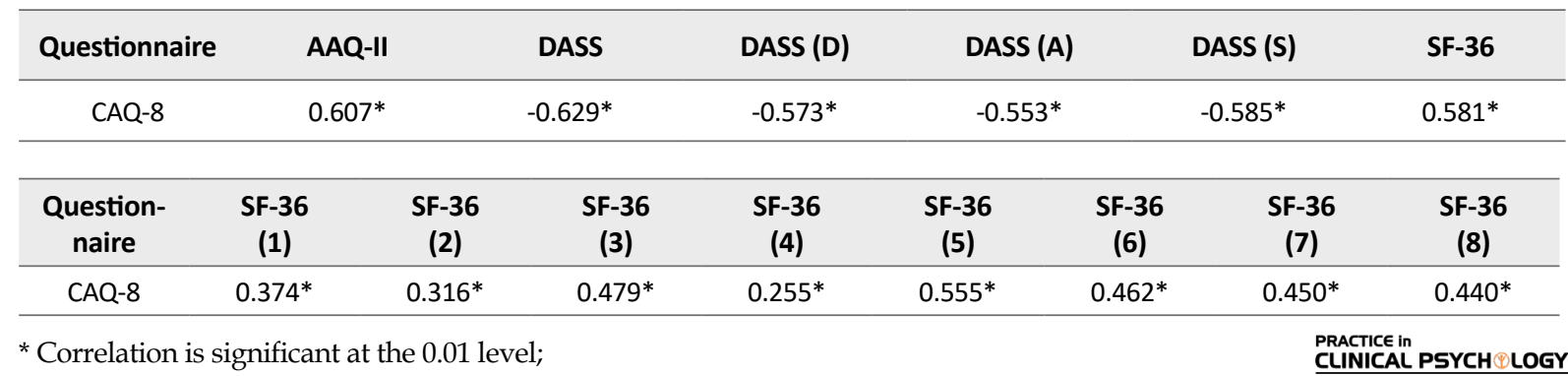

AAQ-II: the total score of acceptance and commitment questionnaire; DASS: total score of depression, anxiety, and stress scale; DASS (D): Depression subscale of DASS-21; DASS (A): Anxiety subscale of DASS-21; DASS (S): Stress subscale of DASS-21; SF36: The total score of Medical Outcomes Study Questionnaire Short Form 36 Health Survey; SF (1): Role performance related to physical problems subscale of SF-36; SF (2): The physical functioning subscale of SF-36; SF (3), mental health subscale of SF-36; SF (4): Role performance related to emotional problems subscale of SF-36; SF (5), the social functioning subscale of SF-36; SF (6): Vitality subscale of SF-36; SF (7): General health subscale of SF-36; SF (8): Bodily pain subscale of SF-36. 
Table 2. The inter-item and item-test correlations

\begin{tabular}{|c|c|c|c|c|c|c|c|c|}
\hline $\begin{array}{l}\text { Question- } \\
\text { naire }\end{array}$ & CAQ.1 & CAQ.2 & CAQ.3 & CAQ.4 & CAQ.5 & CAQ. 6 & CAQ.7 & CAQ.8 \\
\hline CAQ.1 & 1.000 & & & & & & & \\
\hline CAQ.2 & $0.893^{*}$ & 1.000 & & & & & & \\
\hline CAQ.3 & $0.763^{*}$ & $0.765^{*}$ & 1.000 & & & & & \\
\hline CAQ.4 & $0.589^{*}$ & $0.603^{*}$ & $0.614^{*}$ & 1.000 & & & & \\
\hline CAQ.5 & $-0.157^{* *}$ & $-0.183^{* *}$ & $-0.223^{*}$ & $-0.290 *$ & 1.000 & & & \\
\hline CAQ.6 & $0.298^{*}$ & $0.312^{*}$ & $0.239 *$ & $0.299 *$ & $0.162^{* *}$ & 1.000 & & \\
\hline CAQ.7 & $0.313^{*}$ & $0.333^{*}$ & $0.357^{*}$ & $0.416^{*}$ & 0.099 & $0.546^{*}$ & 1.000 & \\
\hline CAQ.8 & $0.151^{* *}$ & 0.133 & $0.153^{* *}$ & $0.249^{*}$ & 0.025 & $0.414^{*}$ & $0.466^{*}$ & 1.000 \\
\hline CAQ-8 & $0.789 *$ & $0.79 *$ & $0.746^{*}$ & $0.704^{*}$ & 0.079 & $0.651^{*}$ & $\begin{array}{l}0.705^{*} \\
\text { PRACTICE In } \\
\text { CUINICAL }\end{array}$ & 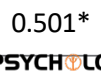 \\
\hline
\end{tabular}

* Correlation is significant at the 0.01 level;

CAQ-8: The total score of committed action questionnaire.

\section{Discussion}

Committed action is a valuable behavior, that can give rise to a cherished life, in which the individuals live ac- cording to their underlying life values (Hayes, Luoma, Bond, Masuda, \& Lillis, 2006; Hayes, Pistorello, \& Levin, 2012). In other words, committed action is a persistent and flexible action that is guided by goals and

Table 3. Descriptive data and standardized regression weights of the Confirmatory Factor Analyses (CFA) for items in the CAQ-8

\begin{tabular}{|c|c|c|c|c|}
\hline Item Number & Item & Mean \pm SD & $\begin{array}{c}\text { Factor } 1 \\
\text { (Positively } \\
\text { Phrased) }\end{array}$ & $\begin{array}{c}\text { Factor } 2 \\
\text { (Negatively } \\
\text { Phrased) }\end{array}$ \\
\hline CAQ.1 & When a goal is difficult to reach, I can take small steps to reach it. & $4.17 \pm 1.80$ & 0.897 & 0.079 \\
\hline CAQ.2 & $\begin{array}{l}\text { I can remain committed to my goals even when there are times } \\
\text { that I fail to reach them. }\end{array}$ & $4.17 \pm 1.82$ & 0.887 & 0.081 \\
\hline CAQ.3 & I prefer to change how I approach a goal rather than quit. & $4.26 \pm 1.62$ & 0.873 & 0.060 \\
\hline CAQ.4 & $\begin{array}{l}\text { I can follow my long-term plans, including times when progress } \\
\text { is slow. }\end{array}$ & $4.28 \pm 1.67$ & 0.752 & 0.176 \\
\hline CAQ.5 & $\begin{array}{l}\text { I find it difficult to carry on an activity unless I experience that it } \\
\text { is successful (r). }\end{array}$ & $2.36 \pm 1.65$ & -0.478 & 0.461 \\
\hline CAQ.6 & If I feel distressed or discouraged, I let my commitments slide (r). & $3.98 \pm 1.67$ & 0.140 & 0.779 \\
\hline CAQ.7 & $\begin{array}{l}\text { I get so wrapped up in what I am thinking or feeling that I cannot } \\
\text { do the things that matter to me }(r) \text {. }\end{array}$ & $4.00 \pm 1.73$ & 0.237 & 0.759 \\
\hline CAQ.8 & If I cannot do something my way, I will not do it at all (r). & $3.84 \pm 1.51$ & 0.028 & 0.722 \\
\hline
\end{tabular}

Table 4. CAQ-Persian version goodness of fit indexes

\begin{tabular}{cccccccccc}
\hline $\boldsymbol{\chi}^{2}$ & $\mathbf{d f}$ & $\boldsymbol{\chi}^{2} / \mathbf{d f}$ & CFI & NFI & RFI & GFI & SRMR & REMSEA & AIC \\
\hline 32.54 & 13 & 2.50 & 0.98 & 0.96 & 0.94 & 0.95 & 0.05 & 0.09 & 856.29 \\
\hline
\end{tabular}

$\chi^{2} /$ df: The relative/normed Chi-Square statistic; $\chi^{2}$ : Chi-Square statistic; df: Degrees of freedom; AIC: Akaike information criterion; CFI: The comparative fit index; RMSEA: The root mean square error of approximation; SRMS: The standardized root mean square residual; GFI: The goodness of fit index; RFI: Relative fit index; NFI: Normed Fit Index. 


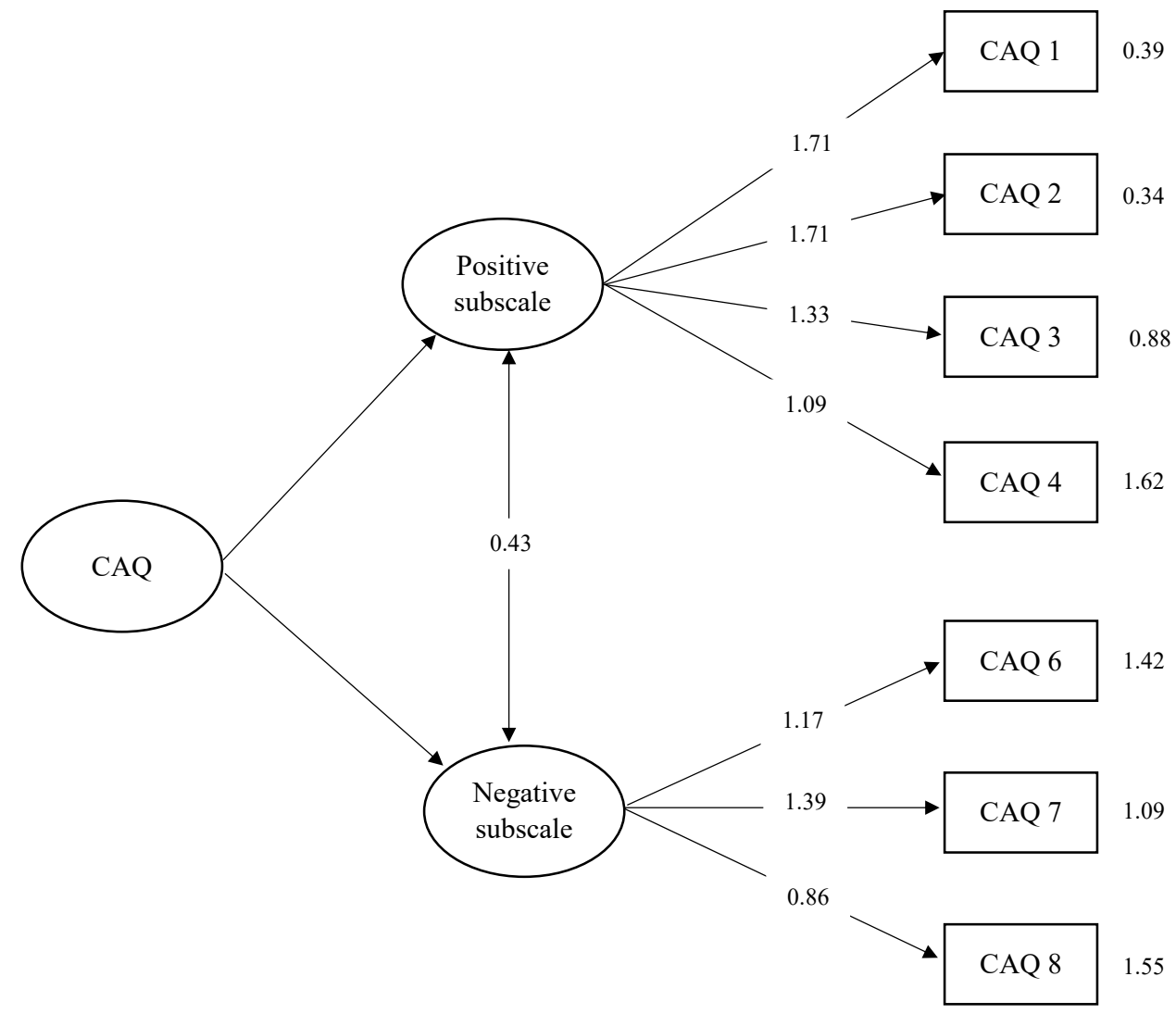

Figure 1. Standardized factor loadings for confirmatory factor analyses

values. Individuals with a higher degree of committed action can follow beneficial goals and give up unsuccessful activities McCracken, Chilcot, \& Norton (2015).

Committed action should be assessed with a valid and reliable measure. Thus, McCracken (2013) developed the first measure of committed action, and subsequently, a shortened version was developed. Both the original and the shortened version demonstrated satisfactory psychometric properties (McCracken, 2013; McCracken, Chilcot, \& Norton, 2015). McCracken and Colleagues argued that committed action can be successfully measured by CAQ-8, and this measure is significantly associated with various aspects of functioning and health McCracken, Chilcot, \& Norton (2015).

The psychometric examination of the CAQ is an important step in the evaluation of the psychological flexibility model in the research and clinical context. As noted by Akerblom et al. (2016), recent studies about psychological flexibility model have concentrated on the variables such as openness and awareness components, and there are inadequate studies about other components such as activation, engagement, and motivation, which can be more fully addressed (McCracken, 2013). Further research is needed to fill out these less-studied fields, and clarify the role of different national contexts and cultures in the psychological assessment.

Furthermore, this study confirmed the previous studies (McCracken, Chilcot, \& Norton, 2015; Trompetter et al., 2013) about the important relationship between committed action and other aspects of psychological flexibility. Similarly, there are negative associations between CAQ-8 and psychopathology (namely, depression and anxiety). The Persian version of the CAQ- 8 had satisfactory psychometric properties in the Iranian sample. Moreover, this instrument revealed high levels of internal consistency and satisfactory validity.

The findings from the current study indicated satisfactory internal consistency, and concurrent validity of CAQ-8 that was consistent with the recent studies (Akerblom et al., 2016; Bailey et al., 2016; Trindade et al., 2018). It indicated that committed action has a significant correlation with several aspects of mental and physical health. 
Regarding the construct validity, the correlation between the CAQ-8 and theoretically-related variables, including acceptance and action, depression, anxiety and stress, and health survey, was examined. Taken together, the Persian version of CAQ-8 demonstrated good construct validity.

It should be noted from the outset that, one item (item 5) had no adequate psychometric criteria for remaining in the Persian version of CAQ. Removal of this item from the questionnaire, dramatically increased the internal consistency, CFA, and also the goodness of fit indexes.

After the deletion of item 5, the internal consistency exceeded from 0.77 to 0.84 according to Cronbach $\alpha$, which made the Persian version of CAQ a reliable questionnaire. Similarly, in CFA of CAQ-8, we extracted two items, which explained $66.48 \%$ of the total variance. After the exclusion of item 5 , this amount increased to $73.25 \%$.

While according to the confirmatory factor analysis and goodness of fit indexes, the two-factor model of CAQ-8 was confirmed in this study, we were unable to retain all items of the original measures. Furthermore, for reaching the goodness of fit model, we had to exclude one item (item 5) from the Persian version of CAQ.

These findings should be considered along with several study limitations. Concerning the cross-sectional nature of this study, the correlation between committed action and other instruments (AAQ-II, DASS-21, and SF-36) should not be considered causal. For causal interference, we require longitudinal designs exploring the relationship of committed action with health and mental functioning. Also, controlled longitudinal studies can clarify the role of committed action in treatment outcome (Akerblom et al., 2016). Moreover, this study restricted to university students, then the generalization of the findings to other populations requires further investigation in various samples. Future research should test additional psychometric properties such as sensitivity to change in interventions targeting committed action. Moreover, we used the Cronbach alpha for CAQ-8 reliability merely. We recommended investigating the test-retest reliability of this measure in future studies.

\section{Conclusion}

Because CAQ was mostly investigated in a medical context and pain-related studies, it is helpful to evaluate the psychometric properties and especially the divergent validity of the CAQ Persian version in a healthy and clinical sample simultaneously. Additionally, examining additional relevant psychometric properties such as other validity in- dicators can strengthen the body of literature and scientific support for CAQ-8 in various contexts and cultures.

\section{Ethical Considerations}

\section{Compliance with ethical guidelines}

All ethical principles were considered in this article. The participants were informed about the purpose of the research and its implementation stages; they were also assured about the confidentiality of their information; Moreover, They were allowed to leave the study whenever they wish, and if desired, the results of the research would be available to them.

\section{Funding}

The present paper was extracted from the $\mathrm{PhD}$. thesis the first author, Department of Clinical Psychology, Faculty of psychology and Education, Kharazmi University, Tehran.

\section{Authors' contributions}

All authors were equally contributed in preparing this article.

\section{Conflict of interest}

The authors declared no conflict of interest.

\section{References}

Abbasi, E., Fati, L., Molodi, R., \& Zarrabi, H. (2013). [Psychometric properties of Persian version of acceptance and action questionnaire -II (Persian)]. Journal of Psychological Models and Methods, 2(10), 65-80. http://jpmm.miau.ac.ir/article_61.html

Akerblom, S., Perrin, S., Fischer, M. R., \& McCracken, L. M. (2016) A validation and generality study of the committed action questionnaire in a Swedish sample with chronic pain. International Journal of Behavioral Medicine, 23(3), 260-70. [DOI:10.1007/s12529016-9539-x] [PMID]

Antony, M. M., Bieling, P. J., Cox, B. J., Enns, M. W., \& Swinson, R. P. (1998). Psychometric properties of the 42 -item and 21-item versions of the Depression Anxiety Stress Scales in clinical groups and a community sample. Psychological Assessment, 10(2), 176-81. [DOI:10.1037/1040-3590.10.2.176]

Asghari, A., Saed, F., \& Dibajnia, P. (2008). Psychometric properties of the Depression Anxiety Stress Scales-21 (DASS-21) in a nonclinical Iranian sample. International Journal of Psychology, 2(2), 82-102. http:/ / www.ijpb.ir/article_55507.html

Bailey, R. W., Vowles, K. E., Witkiewitz, K., Sowden, G., \& Ashworth, J. (2016). Examining committed action in chronic pain: Further validation and clinical utility of the committed action ques- 
tionnaire. The Journal of Pain, 17(10), 1095-104. [DOI:10.1016/j. jpain.2016.06.011] [PMID]

Bond, F. W., Hayes, S. C., Baer, R. A., Carpenter, K. M., Guenole, N., \& Orcutt, H. K., et al. (2011). Preliminary psychometric properties of the Acceptance and Action Questionnaire-II: A revised measure of psychological inflexibility and experiential avoidance. Behavior Therapy, 42(4), 676-88. [DOI:10.1016/j.beth.2011.03.007] [PMID]

Cohen, R. J., Swerdlik, M. E., \& Phillips, S. M. (1996). Psychological testing and assessment: An introduction to tests and measurement. Mountain View, CA: Mayfield Publishing Co. https://books. google.com/books?id=DqWbz4P-AQgC\&dq

Forman, E. M., Herbert, J. D., Moitra, E., Yeomans, P. D., \& Geller, P. A. (2007). A randomized controlled effectiveness trial of acceptance and commitment therapy and cognitive therapy for anxiety and depression. Behavior Modification, 31(6), 772-99. [DOI:10.1177/0145445507302202] [PMID]

Galán, S., Roy, R., Solé, E., Racine, M., de la Vega, R., \& Jensen, M. P., et al. (2019). Committed action, disability and perceived health in individuals with fibromyalgia. Behavioral Medicine, 45(1), 62-9. [D OI:10.1080/08964289.2018.1467370] [PMID]

Hayes, S. C., Luoma, J. B., Bond, F. W., Masuda, A., \& Lillis, J. (2006). Acceptance and commitment therapy: Model, processes and outcomes. Behaviour Research and Therapy, 44(1), 1-25. [DOI:10.1016/j. brat.2005.06.006] [PMID]

Hayes, S. C., Strosahl, K., Wilson, K. G., Bissett, R. T., Pistorello, J., \& Toarmino, D., et al. (2004). Measuring experiential avoidance: A preliminary test of a working model. The Psychological Record 54(4), 553-78. [DOI:10.1007/BF03395492]

Henry, J. D., \& Crawford, J. R. (2005). The short-form version of the Depression Anxiety Stress Scales (DASS-21): Construct validity and normative data in a large non-clinical sample. British Journal of Clinical Psychology, 44(Pt 2), 227-39. [DOI:10.1348/014466505X29657] [PMID]

Ware, J. E. (1993). SF-36 Health Survey. Manual and Interpretation Guide. Boston: Health Assessment Lab, New England Medical Center.

Kaiser, H. F. (1970). A second generation little jiffy. Psychometrika, 35(4), 401-15. [DOI:10.1007/BF02291817]

Kaiser, H. F. (1974). An index of factorial simplicity. Psychometrika, 39(1), 31-6. [DOI:10.1007/BF02291575]

Kline, P. (2013). Handbook of psychological testing. Abingdon: Routledge. [DOI:10.4324/9781315812274]

Knight, G. P., Virdin, L. M., Ocampo, K. A., \& Roosa, M. (1994) An examination of the cross-ethnic equivalence of measures of negative life events and mental health among Hispanic and Anglo-American children. American Journal of Community Psychology, 22(6), 767-83. [DOI:10.1007/BF02521558] [PMID]

Kraiss, J. (2014). Measuring committed action: Psychometric evaluation of the Committed Action Questionnaire (CAQ) in a nonclinical sample [BA. thesis]. Enschede: University of Twente. https:// essay.utwente.nl/65750/1/Krai\%C3\%9F\%2C\%20J.T.\%20-\%20 s1206273\%20\%28verslag\%29.pdf

Lovibond, S. H., \& Lovibond, P. F. (1995). Manual for the depression anxiety stress scales. Sydney: Psychology Foundation of Australia. https://www.worldcat.org/title/manual-for-the-depressionanxiety-stress-scales/oclc/222009504
McCracken, L. M. (2013). Committed action: An application of the psychological flexibility model to activity patterns in chronic pain. The Journal of Pain, 14(8), 828-35. [DOI:10.1016/j.jpain.2013.02.009] [PMID]

McCracken, L. M., Chilcot, J., \& Norton, S. (2015). Further development in the assessment of psychological flexibility: A shortened $\mathrm{C}$ ommitted A ction $\mathrm{Q}$ uestionnaire (CAQ-8). European Journal of Pain, 19(5), 677-85. [DOI:10.1002/ejp.589] [PMID]

McHorney, C. A., Ware Jr, J. E., \& Raczek, A. E. (1993). The MOS 36-item Short-Form health survey (SF-36): II. Psychometric and clinical tests of validity in measuring physical and mental health constructs. Medical Care, 31(3), 247-63. [DOI:10.1097/00005650199303000-00006] [PMID]

McHorney, C. A., Ware Jr, J. E., Rachel Lu, J. F., \& Sherbourne, C. D. (1994). The MOS 36-item Short-Form health survey (SF36): III. Tests of data quality, scaling assumptions, and reliability across diverse patient groups. Medical Care, 32(1), 40-66. [DOI:10.1097/00005650-199401000-00004] [PMID]

Meyers, L. S., Gamst, G., \& Guarino, A. J. (2016). Applied multivariate research: Design and interpretation. Thousand Oaks, CA: SAGE Publications. https://us.sagepub.com/en-us/nam/applied-multivariate-research/book246895

Montazeri, A., Goshtasebi, A., Vahdaninia, M., \& Gandek, B. (2005). The Short Form health survey (SF-36): Translation and validation study of the Iranian version. Quality of Life Research, 14(3), 875-82. [DOI:10.1007/s11136-004-1014-5] [PMID]

Shepherd, L., Reynolds, D. P., Turner, A., O'Boyle, C. P., \& Thompson, A. R. (2019). The role of psychological flexibility in appearance anxiety in people who have experienced a visible burn injury. Burns, 45(4), 942-9. [DOI:10.1016/j.burns.2018.11.015] [PMID]

Spss, I. (2016). Statistics for Windows, Version 24. 0 [Computer Software]. Armonk, NY: IBM Corp. https://www.ibm.com/support/pages/downloading-ibm-spss-statistics-24

Stevens, J. P. (2012). Applied multivariate statistics for the social sciences. New York: Routledge. https://books.google.com/ books?id=oleDhzDebKwC\&dq

Tabachnick, B. G., \& Fidell, L. S. (2013). Using multivariate statistics, Upper Saddle River: Pearson Education. https://books.google. com/books?id=ucjlygAACAAJ\&dq

Trindade, I. A., Marta-Simões, J., Ferreira, C., \& Pinto-Gouveia, J. (2018). Developments on committed action: Validity of the CAQ-8 and analysis of committed action's role in depressive symptomatology in breast cancer patients and healthy individuals Clinical Psychology \& Psychotherapy, 25(1), e42-e50. [DOI:10.1002/ cpp.2125] [PMID]

Trompetter, H. R., Ten Klooster, P. M., Schreurs, K. M. G., Fledderus, M., Westerhof, G. J., \& Bohlmeijer, E. T. (2013). Measuring values and committed action with the Engaged Living Scale (ELS): Psychometric evaluation in a nonclinical sample and a chronic pain sample. Psychological Assessment, 25(4), 1235-46. [DOI:10.1037/ a0033813] [PMID]

van Prooijen, J. W., \& van der Kloot, W. A. (2001). Confirmatory analysis of exploratively obtained factor structures. Educational and Psychological Measurement, 61(5), 777-92. [DOI:10.1177/00131640121971518]

Ware Jr, J. E., \& Gandek, B. (1998). Overview of the SF-36 health survey and the International Quality of Life Assessment (IQOLA) pro- 
ject. Journal of Clinical Epidemiology, 51(11), 903-12. [DOI:10.1016/ S0895-4356(98)00081-X]

Ware Jr, J. E., \& Sherbourne, C. D. (1992). The MOS36-item shortform health survey (SF-36): I. Conceptual framework and item selection. Medical Care, 30(6), 473-83. [DOI:10.1097/00005650199206000-00002] [PMID]

Watkins, D. (1989). The role of confirmatory factor analysis in cross-cultural research. International Journal of Psychology, 24(6), 685-701. [DOI:10.1080/00207598908247839]

Wong, W. S., McCracken, L., Wong, S., Chen, P. P., Chow, Y. F., \& Fielding, R. (2016). The Chinese version of the 8-item Committed Action Questionnaire (ChCAQ-8): A preliminary analysis of the factorial and criterion validity. Psychological Assessment, 28(6), e111-e8. [DOI:10.1037/pas0000187] [PMID] 